\title{
Bubbles, Busts, and Blame
}

by ROBERT HOCKETT, PROFESSOR OF LAW, CORNELL LAW SCHOOL

Ours are tough times for the image of bankers and other financial professionals. The harms being suffered by many on "Main Street" are of obscure origin to most who inhabit that Arcadian precinct. Folk sense that "Wall Street" has something to do with their pain, but know little if anything more than that. Inexplicable pain of this sort seems quite often to issue in blame. There is a natural urge to know why one is suffering, after all; and when we

Professor Whitehead also takes on this topic on page 18. can point to some devil or scapegoat in some such mysterious, alien locale as "the banks" or "the financial district," the pain grows apparently somewhat more bearable. It is not then the product of victims'-or public_incompetence. Yes, as seductive explanatory stories go, bad guy cupidity beats good guy stupidity hands down.

I am happy enough to concede there were "bad guys" involved in our most recent experience of speculative mania and subsequent meltdown. There always are in such cases. Nor do I doubt there was plenty of "good guy" stupidity here too. There always is in such cases. What seems to me more interesting, however, is how inessential these presences-which again always are with us, in good times and bad-are to explaining what happened. There's no need to blame any market actor, or even any market, in accounting for what happened. The relevant story is elsewhere. I think it will be useful to tell it. That will be fairer both to the innocents - the great majority, after all-and to the cause of our finding such cures as can prevent a recurrence.

So what is this "relevant story?" What we have just been through, I believe, is a classic asset price bubble and burst. And these bubbles and bursts, I shall argue, are best viewed as near textbook cases of collective action problems. The hallmark of such problems is this: multiple acts even of ethically unobjectionable individual rationality aggregate into collectively irrational—even calamitous-outcomes. The wearisomely familiar "prisoner's dilemma" that graces most game theory texts of course is the best known example-unless that be the likewise familiar "tragedy of the commons." But there are many others, some only marginally less familiar, worth recalling: arms races, bank runs, economy-wide layoffs, "liquidity traps," recessionary spiralseven consumer price inflations, to name but a few.

It doesn't seem widely appreciated that asset price bubbles and busts are of the same form-indeed, that they are effectively hyper- inflations. That is a pity. For once we see this, we no longer feel certain that there must be scoundrels or idiots behind every travail like that we're now suffering. We become less inclined to cast blame. We turn instead to the search for constructive solutions.

Let us talk first about asset price bubbles and bursts, then. After that I shall speak of solutions.

Asset price bubbles and bursts, along with the credit and monetary contractions that characteristically follow them, recur with depressing regularity through the course of financial history. ${ }^{1}$ The same regularity characterizes the soul-searching and lessonseeking that seem always to follow these cataclysms. ${ }^{2}$ Given the regularity both of these occurrences and of our subsequent efforts to diagnose and treat them, one might have hoped we'd have reached "the end of [this] history" by now. Yet it seems we have not. Why?

One reason might be that each asset price bubble bears its own characteristic features. In particular, each bears its own underlying asset or set of such assets, and its own species of financial chicanery that seem always to come to light just as each bubble's limits are neared. ${ }^{3}$ Hence it never is easy to predict the precise place the next bubble might begin to inflate, or where financial abuses are apt to occur. There is surely some truth in this hypothesis. Financial regulators seem doomed often to plan for the last crisis much as generals are said to plan for the last war. Yet I doubt that this truth is the relevant truth we are after, for reasons I'll presently explain.

14 | FORUM | Spring 2011 


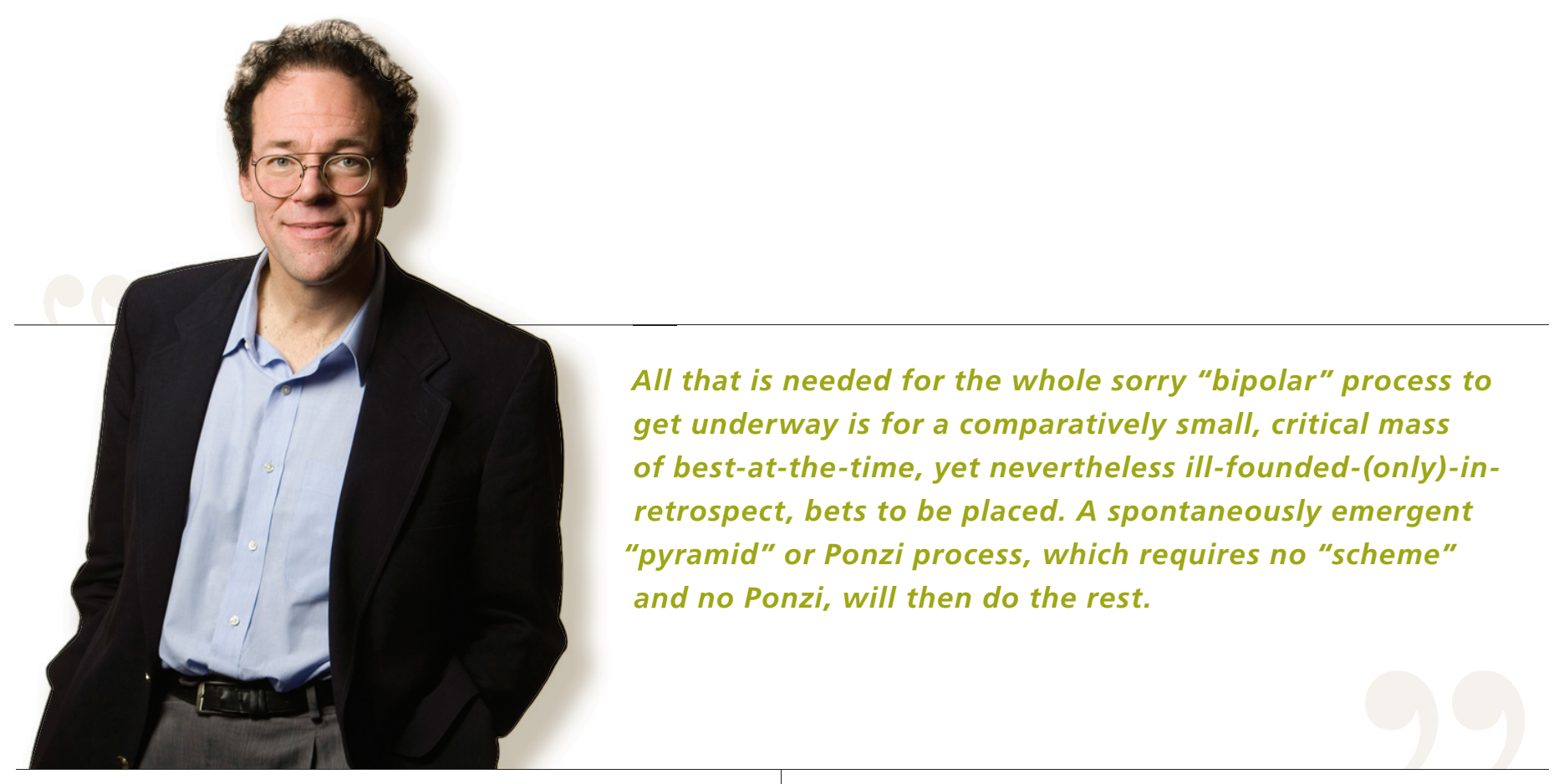

Another, more apposite reason for asset price bubbles' regular recurrence might be our tendency, precisely by dint of our inclination to probe the unique characteristics of each new bubble and burst that occur, to overlook the invariant foundational structure that all asset price bubbles share. This tendency is especially pronounced when influential lay and expert opinion alikeincluding, conspicuously, regulatory opinion-harbor views of financial markets that they erroneously take to be incompatible either with the existence or, by way of fallback position, with the pre-crash discernibility, of any such "foundational structure." ${ }^{\prime 4}$

My own view, I have intimated, is that there is an invariant structure common to all asset price bubbles and bursts; that this structure is discernible even while bubbles are in the process of inflating; and that popular lay, professional, and regulatory opinion have lost sight of it owing to two misapprehensions. Those are that asset price bubbles and/or their detectability prior to bursts would be incompatible with (1) efficiency on the part of financial markets, and/or (2) rationality on the part of market actors. The efficiency hypothesis in turn seems both theoretically warranted and empirically well corroborated; while systematic irrationality for its part seems wildly implausible, not to say oxymoronic in the very naming. And so, the line of thought that I have in mind here concludes, it is the suggestion that bubbles are possible or detectable at all that must be rejected. Call these the "efficiency-incompatibility" and "rationality-incompatibility" theses, respectively.

Why do I say "misapprehension" in connection with these two theses? Two reasons. First, because the kind of efficiency that is in play when we speak of efficient capital markets is primarily, at least in the short run, informational efficiency, while only derivatively-and in the longer run, with plenty of pitfalls along the way-allocative efficiency. What the markets do efficiently in the short run, in other words, is to impound price-relevant information. And the "information" in question here notoriously excludes potential value-relevant data that simply remains, for indefinite periods of time, unavailable.

The information that capital markets efficiently aggregate excludes, in other words, the stuff of radical "Knightian" or "Keynes Chapter 12" uncertainty. That is data in respect of which market participants must in effect take positions, but which positions in turn have to be decided on the basis of generally serviceable conventions and heuristics, "best guesses," "gut feelings," or even "animal spirits" rather than plausibly assignable probability distributions. These are the kinds of decision that a still very few pathfinders now seek to model through non-probabilistic "infogap" decision theory, rather than Bayesian models of the sort suited to actuarial "risk" as distinguished from uncertainty. ${ }^{5}$ And perhaps unsurprisingly, the jury will be out for a while on whether these new non-Bayesian models can handle Knightian uncertainty any better than do the old Bayesian stalwarts.

It also is important to understand informational efficiency not only in respect of what it excludes, but likewise in respect of what it includes: that "information" notoriously includes, again at least in the short run, both (1) advertently and inadvertently propagated "misinformation" nicely suited to filling the gap that is Knightian uncertainty, and relatedly (2) "beautiful baby" and cognate forms of "noise" information. It includes, that is to say, information about how others are presently valuing the asset in question via their trading behavior, which itself can in turn be the product of how yet others appear to be presently valuing the asset in question via their trading behavior, and so on . . . etc. ${ }^{6}$ Price movements prompted by trading on this sort of informa-

16 | FORUM | Spring 2011 
tion can, of course, readily become self-amplifying-the very antithesis of self-equilibrating.

Where efficient informational inclusion is concerned, in other words, positive feedback loops can amplify and distort, at least for several-year intervals, the more accurate "fundamental value" signals that informationally efficient market prices tend in the longer run to convey. Think of them as the positive flipside of those self-fulfillingly prophetic "runs" on assets that always follow on bubbles, the stuff of "busts." For that is just what they are-they are "bank runs in reverse," so to speak. ${ }^{7}$ All that is needed for the whole sorry "bipolar" process to get underway is for a comparatively small, critical mass of best-at-the-time, yet nevertheless ill-founded-(only)-in-retrospect, bets to be placed. A spontaneously emergent "pyramid" or Ponzi process, which requires no "scheme" and no Ponzi, will then do the rest. ${ }^{8}$ The oft-encountered quips of wags, pundits, and too many scholars to the contrary notwithstanding, little to none of this is in tension with the informational efficiency hypothesized by the Efficient Capital Markets Hypothesis. ${ }^{9}$

So much for the efficiency-incompatibility thesis. How about the putative rationality-incompatibility of asset price bubbles? Well, just as asset price bubbles are not incompatible with the relevant form of "efficiency" thought to characterize asset markets, neither are they with the relevant form of "rationality." Once again, much popular parlance to the contrary notwithstanding, there is no tension between rationality on the part of individual financial market actors, on the one hand, and occasionally calamitous outcomes of interactions among multiple such actors on the other hand. To suppose that there is is to commit a fallacy of composition-to confuse a whole with the unstructured sum of its parts. It is also to overlook the commonplace, long familiar to game theory and folk wisdom alike, that multiple acts of individual rationality can under some circumstances aggregate into forms of collective irrationality.

Indeed, our recent bubble and burst in mortgage-backed securities and associated financial instruments, just like previous asset price bubbles, can readily be modeled as a variant of the familiar "prisoners' dilemma" and "chicken" games regularly encountered in microeconomic and game theory texts. ${ }^{10}$ In particular, it can be viewed as the upshot of a stylized game of James Dean-style drag race "chicken."11

In my version of the game, justifiably self-confident, forward-wise blindfolded contestants drive speedily toward a cliff's edge known to be far distant but not how far distant. They are paid by the foot to proceed for as long as-but only for as long as - they outpace others whom they can see to their sides and behind. Finally, they know there are multiple safety nets over the cliff's edge in any case for at least some who don't manage to "bail" in time to avoid going over. It is far from clear that there's any irrationality on the part of any participant in this game. Each stands a good chance of bailing before going over, and of falling into a net if she does. And each stands to grow rich on the way.

The blindfolds in my stylized game of course correspond to the radical uncertainty that attaches to any bubble's limit point; even those who know we're in bubble territory know that there's generally no way to know when the party will end. Payment by the foot corresponds to the fact that all players grow richer the closer they draw to the endpoint, legging the spread between low borrowing costs and high capital gains rates. Finally, the nets of course correspond to the bailouts that many know they are apt to receive. No asset price bubble or bust over the past millennium fails to feature these characteristics.

And it is precisely here, I suggest, that we find the "basic structure" to which I have referred-the structure that's common to all asset price bubbles and bursts. When bubbles develop and inflate per this structure, all manner of behavior that ordinarily looks profligate or cavalier comes to look rather more prudent and prosaic. Purchasing a home or related asset with a lowfront-end, "balloon"-rate mortgage, for example, looks sensible; for throughout the bubble's duration you can always cheaply refinance your loan on the strength of the rapidly appreciating collateral-the house or other asset-before the balloon rate kicks in. Lending to borrowers with less stellar credit histories looks safer for the same reason-the collateral's continually rising price offsets the added default risk-so credit continues to flow,

Once the limit point is reached, however, all turn abruptly and retrace their steps in reverse. The bubble deflates down the same path along which it inflated. The race back to the starting line artificially deflates asset values just as the race to the cliff's edge artificially inflated them-even good assets are viewed as lemons. 
and debt rates continue to grow. Like remarks hold in respect of the good ratings that mortgage-backed instruments received for a while, and of the relaxed attitudes shown by some of our piecemeal—non-"systemic" — regulators like the SEC. For again, the hallmark of that collective action problem known as an asset price bubble just is that each actor's actions are indeed rational, so long as all other actors remain able to keep acting as they have been acting. And it is only when indefinitely extensible credit's never-precisely-foreseeable limit-point is reached that the latter proviso can no longer be counted on.

Once the limit point is reached, however, all turn abruptly and retrace their steps in reverse. The bubble deflates down the same path along which it inflated. The race back to the starting line artificially deflates asset values just as the race to the cliff's edge artificially inflated them-even good assets are viewed as lemons. Previously boom-sustained debt now becomes "overhang," no longer supported by highly market-valued collateral. Defaults ensue, first among borrowers, then among their lenders, then among lenders to lenders, and so on. Credit contracts systemwide, just as mercurially as it formerly expanded. Business investment soon follows suit. Firms tighten belts, employees are laid off, consumer expenditures thus drop, firms accordingly contract further, and so on-as the boom's feedback process morphs into the bust's feedback process. Same collective action problem, now tacking south rather than north.

So there we have bubbles and busts and their structure. How about solutions?

Solutions to collective action problems, unsurprisingly, require collective agents-agents who act in the name of all to render it no longer individually rational for non-collective actors to make decisions that aggregate into collectively irrational outcomes. In effect, that is how the Fed and Treasury behaved in the autumn of 2008 during the downside. TARP recouped most of its bailout moneys precisely because it brought into one portfolio securities that were undervalued by holders of multiple portfolios during the "downside" collective action problem that is a bust. But what about the "upside" — who serves as collective agent during a "boom" or a bubble?

That, I maintain, would be a macro-prudential, or "systemic risk," regulator-an authority charged with overseeing and modulating price behavior in the credit-monetary-financial system as a whole rather than simply one sector of it. In particular, this regulator would monitor both (1) the growth of leverage rates across the economy as a whole and (2) the growth of spreads between market prices on the one hand and proxies for "fundamental" value on the other. As those rates and spreads moved into selfamplifying territory, she would steadily tighten credit, increasingly tax short term capital gains, or both. There are multiple levers by which this can be done-including Federal Funds rate management, open market operations, reserve requirements, capital regulation, deposit insurance charges, "Tobin" taxation, and others. ${ }^{12}$ But in order for it to be done, the regulator must of course understand her role as a collective agent-a desideratum that sits in some tension with devotion to, say, the ideology of Ayn Rand. ${ }^{13}$

We had something much like the required collective agent overseeing the credit-monetary-financial system for a surprisingly lengthy, more or less bubble-free while: the Fed in the course of the 1950s, early-to-mid-1960s, and early-to-mid-1980s, when the likes of Chairmen William McChesney Martin and, later, Paul Volcker took seriously the Fed's role as countercyclical macroeconomic stabilizer. ${ }^{14}$ Both of those well regarded custodians of our credit-money system seem to have understood the systemic prisoners'-dilemma-like structure of asset price bubbles and consumer price inflations alike. ${ }^{15}$ And so both employed the Fed's principal systemic levers to "lean against the wind" and "take away the punch bowl just as the party was getting good" in order to stabilize asset and consumer price inflations. ${ }^{16}$ Volcker's immediate successor, Chairman Greenspan, alas, saw things differently, succumbing by turns to the efficiency- and rationalityincompatibility theses that I sought to dispel just above. Unless and until we fully reinstate the Fed's-or some counterpart systemic regulator's, such as the new Dodd-Frank-instituted Systemic Risk Council's - role as envisaged by such former chairs as Martin and Volcker, I fear, we are probably destined to continue our cycle of repeated asset price bubbles and bursts, with all the lost wealth and lost health and "lost decades" that this always seems to entail. ${ }^{17}$

We could pull that off partly by choosing our Fed chairs more wisely than we did from the late 1980s until recently. More securely, we would clarify the Fed's mandate to make clear that overheated asset price inflation, as measured against suitable proxies for "fundamental value" (such as home building costs and rental rates in frothy housing market areas), is as inimical as is consumer price inflation to those "stable prices" that the Fed already is charged with "promoting."18 Ultimately, however, we'll have also to bring more institutions and markets-notably hedge funds, money funds, repo and currency markets-under the credit-supervisory umbrella. For, unlike in Martin's and 


\section{... the primary remedial end seems to me clear: close spreads between borrowing rates on the one hand, and bubble-sized asset price inflation rates-as operationally distinguished from "fundamental" value appreciation rates- on the other.}

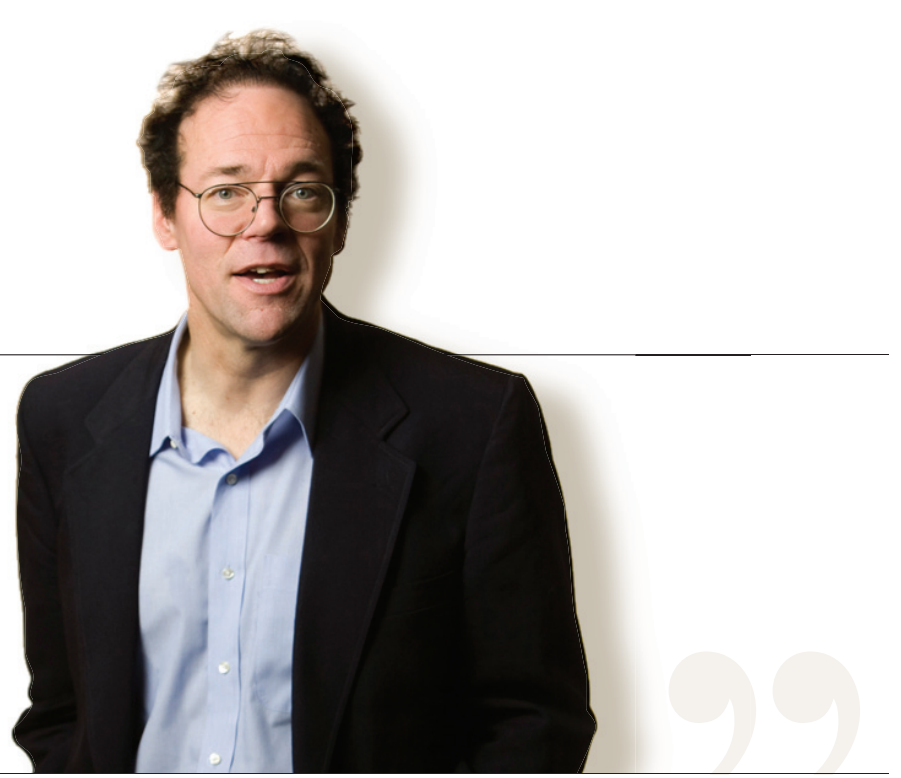

even in Volcker's day, in our day it's no longer commercial banks that are the principal sources of bubble-fueling credit.

Whatever the means upon which we ultimately agree, the primary remedial end seems to me clear: close spreads between borrowing rates on the one hand, and bubble-sized asset price inflation rates-as operationally distinguished from "fundamental" value appreciation rates-on the other. To do that requires first that we recognize bubbles' and busts' compatibility with informational efficiency, market actor rationality, and, indeed, even absence of blame.

1. Pun on "depressing" foreseen but not intended. For histories of financial crises and ensuing contractions, see, e.g., Charles Kindleberger's classic, now in its 5 th edition with a new coauthor, Charles P. Kindleberger \& Robert Aliber, Manias, Panics, and Crashes: A History of Financial Crises (5th ed., 2005). Another recent treatment, this one a bit more teched-up with quantitative analyses, is Carmen M. Reinhart \& Kenneth S. Rogoff, This Time Is Different: Eight Centuries of Financial Folly (2009).

2. For two early—not to say diverting—examples, see, e.g., Joseph de la Vega, Confusión de Confusiones (Martin S. Fridson ed., 1996 [1688]), and Charles MacKay, Extraordinary Popular Delusions and the Madness of Crowds (Martin S. Fridson ed., 1996 [1841]).

3. The chicanery, as it happens, seems seldom if ever to constitute a significant cause of asset price bubbles or bursts, only a symptom that manifests late in the game. See Robert Hockett, “A Fixer-Upper for Finance," 87 Wash. U. L. Rev. 1213 (2010).

4. Call the first view the "ontic"view, and the second view the "epistemic" fallback. Former Fed Chairman Greenspan, for one, appears to have held each of these views at various points of his tenure.

5. Much more on this in Hockett, "Fixer-Upper," supra note 3. On “Knightian" uncertainty, see of course Frank H. Knight, Risk, Uncertainty, Profit (1921). “Keynes Chapter 12" uncertainty alludes to Chapter 12 of Keynes, The General Theory of Employment Interest and Money (1936) wherein also can be found the coining of the term "animal spirits" as employed in financial market contexts. See also John Maynard Keynes, A Treatise on Probability 75-76, 315 (1921); and Daniel Ellsberg, “Risk, Ambiguity, and the Savage Axioms," 75 Q. J. Econ. 643 (1961). For more on non-Bayesian "info-gap" decision theory and its possible suitability to radically uncertain decision-making contexts, see, e.g., Yakov Ben-Heim, Info-Gap Decision Theory: Decisions Under Extreme Uncertainty (2d ed., 2006).
6. "Beautiful baby" and"noise" information originate, respectively, with Keynes, supra note 5 at 156, and Fischer Black, "Noise," 41 J. Fin. 529 (1986). For more on all of this, see again Hockett, supra note 3 .

7. See again Hockett, “Fixer-Upper," supra note 3 for much more on this.

8. A fair bit has been written of late on positive feedback loops in asset pricing and their roles in bubble-inflation. See, e.g., Franklin Allen et al.,"Beauty Contests and Iterated Expectations in Financial Markets,"19 Rev. Fin. Stud. 719 (2006). A superb synthesis of his own many illuminating articles on the matter is Hyun Song Shin, Risk and Liquidity (2010). See also Hockett, supra note 3, and Robert Hockett, Bretton Woods 1.0 (working paper) for much more on the matter. The idea of a "naturally occurring Ponzi process" of course figures

9. See, of course, Eugene Fama, “Efficient Capital Markets: A Review of Theory and Empirical Work," 25 J. Fin. 383 (1970). Also Eugene Fama, “Efficient Markets: II," 46 J. Fin. 1575 (1991).

10. See again Hockett, “Fixer-Upper," supra note 3. See also my posting on the subject on the Dorf on Law weblog this past September, available at www.dorfonlaw.org/2009/09/ what-maynard-keynes-james-dean-and-now.html.

11. The typical game of "chicken" differs the generic "prisoners' dilemma" game in one important respect: retaliation constitutes the best non-cooperative strategy in the latter case but not in the former, since retaliation in the former results in the death of both players. The variant of "chicken" that I model here, possessed as it is of "safety nets," accordingly lies somewhere between garden variety" chicken" and "prisoners' dilemma."

12. See again Hockett, “Fixer-Upper," supra note 3 for detail.

13. The allusion is to former Fed Chairman Alan Greenspan's devotion to Ms. Rand.

14. See again Hockett, "Fixer-Upper," supra note 3 for more on this history.

15. Consumer price inflation is characterized by the same prisoners' dilemma structure as characterizes asset price bubbles, which indeed can be viewed simply as cases of asset price hyperinflation. Again see Hockett, “Fixer-Upper," supra note 3.

16. The quoted nostrums were popularized by Martin. See id.

17. With"lost decade,"I am alluding to the protracted slump, now rather more than a decade in duration, that Japan has suffered since the collapse of its stock and commercial real estate price bubbles of the late 1980s. With “lost health,"I am alluding to a recent report in the New York Times on the health consequences of long-term unemployment. Finally, capacity-underutilization, as during recessions.

18. See 12 USC $225 a$ prominently in Robert J. Shiller, Irrational Exuberance (2000). with "lost wealth,"I am alluding to all of the production that is foregone during periods of 